\title{
IRON DEPOSITION IN THE GROWTH PLATE OF LONG BONES OF THE OFFSPRING WHEN GIVEN DURING PREGNANCY IN RAT MODEL
}

\author{
Faiza Umbreen, Khadija Qamar, Sadia Shaukat*, Maimoona Khan ${ }^{* *}$, Sana Malik ${ }^{* * *}$, Hussain Ali**** \\ Army Medical College/National University of Medical Sciences (NUMS) Rawalpindi Pakistan, *Rehman Medical College Peshawar Pakistan, **University of \\ Zimbabwe, Harare, Zimbabwe, ${ }^{* * *}$ Federal Medical and Dental College, Islamabad Pakistan, ${ }^{* * * *}$ National Institute of Health, Islamabad Pakistan
}

\section{ABSTRACT}

Objective: To evaluate histologically the deposition of iron in the epiphyseal cartilage of offspring's of dams given iron supplementation during pregnancy and lactation in rat model.

Study Design: Laboratory based experimental study.

Place and Duration of Study: Department of Anatomy, Army Medical College, Rawalpindi and National Institute of Health (NIH) Islamabad, from Mar to Nov 2016.

Methodology: In this study, 16 female and 4 male adult rats were chosen for breading. After confirmation of pregnancy, pregnant rats were separated in two groups. One group was given oral iron supplementation for four weeks till delivery and half of the pups fed by mothers who were given iron during lactation. The other group was kept on normal lab diet. Deposition of iron in the epiphyseal cartilage of newborn rats after four weeks was evaluated histologically in pups.

Results: Iron deposition was maximum in group C i.e. $1.30 \pm 0.48$; in group B it was $0.20 \pm 0.44$. Statistically significant iron deposition $(p<0.001)$ was observed in the growth plate of off springs when mothers were given iron supplements during pregnancy and lactation.

Conclusion: Present study proves that injudicious iron supplementation through pregnancy results in deposition of iron in epiphyseal growth plate of the fetus and it can have damaging effects on bones of fetus.

Keywords: Epiphyseal cartilage, Iron deposition, Pregnancy.

This is an Open Access article distributed under the terms of the Creative Commons Attribution License (https://creativecommons.org/licenses/by-nc/4.0/), which permits unrestricted use, distribution, and reproduction in any medium, provided the original work is properly cited.

\section{INTRODUCTION}

Iron supplementation during pregnancy is recommended in third world countries as iron deficiency anemia is common. Iron supplementation has some side effects as it gets accumulated in different tissues in the body e.g. liver, heart, and endocrine glands, leading to cirrhosis, cardiomyopathy, diabetes mellitus, and other endocrinopathies ${ }^{1}$.

There is a proof of the adverse secondary effects caused by excess hemoglobin and increased serum ferritin levels in pregnancy. Women with raised serum ferritin levels in the last trimester of pregnancy, perhaps related with overload of iron, have a significantly increased chance of preterm delivery.

Iron supplementation during pregnancy is routinely done ${ }^{2}$. According to World Health Organization, about 2 billion of the world's population is anemic, though occurrence rates are variable because of differences in socioeconomic conditions, routines, food consumption, and rates of different diseases. Iron deficiency is the most common cause of anemia and is the most prevalent especially in pregnant women. According to recent recommendations of the Center of Dis-

Correspondence: Dr Faiza Umbreen, Department of Anatomy, Army Medical College Rawalpindi Pakistan

Received: 12 Apr 2020; revised received: 01 Jan 2021; accepted: 06 Jan 2021 ease Control, anemia in pregnancy is labelled by a hemoglobin level $<10.5 \mathrm{~g} / \mathrm{dl}$. Another indication of the unwanted effects caused by excess hemoglobin is the high ferritin levels due to the failure of maternal plasma volume to expand ${ }^{3}$. Iron deficiency (ID) is the most common micronutrient deficiency in children. Universal problem of ID assessed to be $43 \%$ worldwide in $2011^{4}$.

Iron is measured the second most ample metal in nature and is crucial for many biological processes. It catalyzes the formation of free radicals through the Haber-Weiss reaction, triggering oxidative stress in different cells ${ }^{5}$. Iron is vital for hemoglobin production, and metabolic activities. It is found in foods from animal as well as plant sources, as well as fortified cereal foods ${ }^{6}$. Normal iron levels are strongly controlled, with increased intestinal absorption and cellular uptake transferrin receptor in reduced states. Iron supplementation is suggested to pregnant women at danger of anemia, lasting after delivery. However, debate exists about iron supplementation to all pregnant women due to unfavorable effects of iron excess. Oral ferrous preparations leading to elevated non-transferrin-bound iron, aggravate inflammation and oxidative stress. Free iron is extremely reactive and can lead to free radical damage; There is some clue that co-treatment of non-pregnant rats with anti-oxidants, e.g. vitamin $\mathrm{E}$ 
and $\mathrm{C}$, is defensive against oxidative damage, suggesting more research is needed into multi-therapeutic methods ${ }^{7}$.

As showed by other studies different drugs and chemicals given during pregnancy are accumulated in the growth plate of fetus and produce their effects as shown by a research ${ }^{8}$, For example Dexamethasone (DEX.) administration considerably reduced the thickness of the hypertrophy zone of the growth plate ${ }^{9}$, it also disturbed the structure of collagen fibers, dropping the proportion of thin fibers. Similarly the exposure to glucocorticoids in pregnant spiny mice affects cartilage development by accelerating maturity of collagen fibers and growth plate, apparently along with further disturbance of longitudinal growth of long bones ${ }^{10}$. Objective of the study was to study the presence of iron deposition in the epiphyseal cartilage of off springs when given to pregnant rats.

\section{METHODOLOGY}

It was laboratory based experimental study conducted at department of Anatomy, Army Medical College, Rawalpindi, from March to November 2016. The protocol of study was approved by Ethics Committee of Centre for Research in Experimental and Applied Medicine (CREAM), Army Medical College, Rawalpindi (Letter no. ERC/SA-16).

Sixteen adult female and four male sprague dawley rats, weighing on average $250 \mathrm{gm}$ and four weeks of age were selected from the animal house of National Institute of Health (NIH), Islamabad. They were retained at standard temperature $21 \pm 2{ }^{\circ} \mathrm{C}$ in a room sustained on 12 hour light/dark cycle ${ }^{11}$. They were given regular NIH laboratory diet ${ }^{12}$, and water ad libitum. They were maintained on breeding with one male for four females ratio. Breeding was arranged at NIH Islamabad animal house, where four female rats were placed with a male in one cage ${ }^{12}$. Female rats were daily checked in the morning for vaginal plug ${ }^{13}$. The presence of the vaginal plug was designated as gestation day zero (GD 0) for starting the iron supplementation. The pregnant rats were randomly divided into two groups. The group 1 contained six rats. It was kept on the standard diet throughout the experiment. Group 2 contained ten rats. In group 2 each pregnant rat was treated with iron syrup in a dosage of $0.5 \mathrm{ml}$ daily for 4 weeks. Every $0.5 \mathrm{ml}$ contains about $2.7 \mathrm{mg}$ of elemental iron which is equivalent to the adult human dose of $10 \mathrm{mg} / \mathrm{kg} /$ day. After spontaneous vaginal delivery pups were divided in three groups each comprising of ten pups. Group A comprising of ten pups of mothers on standard lab. Diet, group B comprising of ten pups of mothers given iron supplementation during pregnancy only and standard laboratory diet during weaning and group $C$ ten pups of mothers given iron supplementation during pregnancy and lactation. After four weeks' time the male and female rats from group A, B and C (pups) of 4 weeks age were euthanized. Ether anesthesia was used for this. The right leg of each animal was dissected and right femur was detached after dividing it from hip and knee joints. Femurs were then placed in 10\% formaldehyde solution. Longitudinal bone sections of 5 micrometer thickness were obtained using rotary microtome. Sections were then stained with Perl's stain ${ }^{14}$, for the detection of iron in the cartilage matrix. Iron deposition in chondrocytes and in matrix. Iron deposition inside and outside the chondrocyte lacunae was measured on Perl's staining, Scoring of iron deposition was done on the basis of scale from 0 to 4 in four different quadrants of the slide ${ }^{15}$. Scoring was done as following: $-0=$ No Perl's positive cells at high power field (40X) chosen at random, $1 \leq 10$ Perl's positive cells at high power field (40X) chosen at random, $2=20$ Perl's positive cells at high power field (40X) chosen at random, $3 \leq 30$ Perl's positive cells at high power field (40X) chosen at random, $4 \geq 30$ Perl's positive cells at high power field (40X) chosen at random.

Sony digital camera (16 megapixel), and Olympus digital camera (10 mega pixel) stylus 1010 were used through the ocular of the Olympus DP21 light microscope. Data was inserted in data base using statistical package for social sciences (SPSS-21). For quantitative data mean \pm SD was calculated, the means were compared for significance amongst groups using one way analysis of variance (ANOVA) followed by post hoc Tukey test for comparison.

\section{RESULTS}

Iron deposition in the epiphyseal cartilage inside the chondrocytes and in the matrix is established in the study. Perl's staining demonstrated the iron as dark blue color deposits as amorphous deposits as well as in the clusters. Scoring of iron deposition in chondrocytes and matrix was analyzed (figure). There was no iron deposits in group A which was control group. Some iron deposition was seen in experimental group B which was scored as 1 and in group $C$ it was scored as 2 ( 3 slides only). It was maximum in group $\mathrm{C}$. The mean \pm SD A group was $0.00 \pm 0.00$, in group B it was $0.20 \pm 0.44$ and in group C it was $1.30 \pm 0.48$ (table-I). Inter-group comparison (Post Hoc analysis) was 


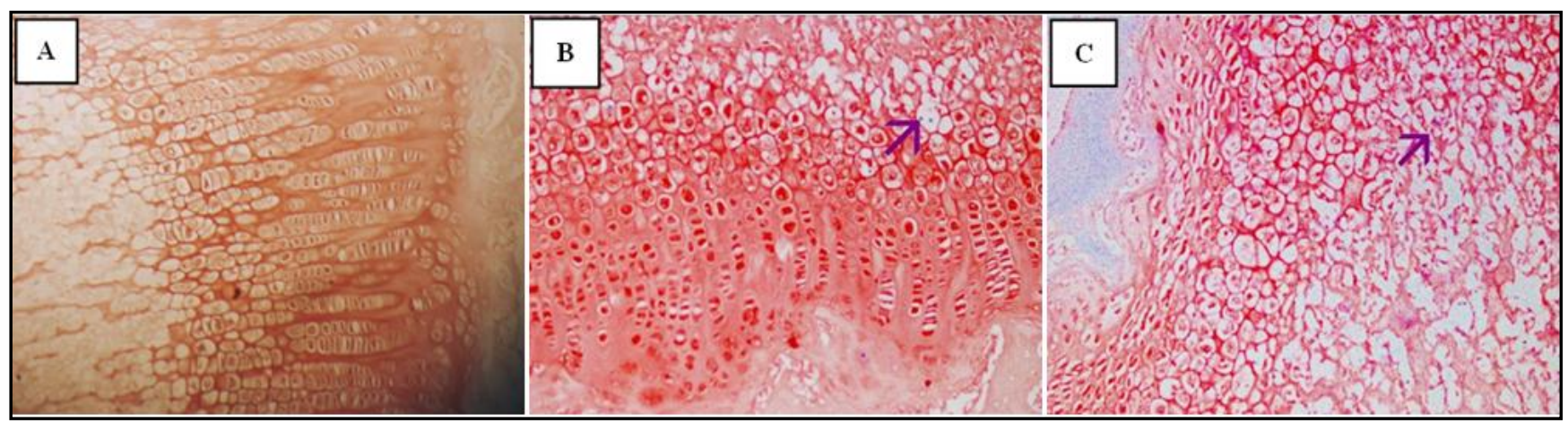

Figure: Photomicrograph of histological section of epiphyseal cartilage showing A): Control group A B): Experimental group B, C): Experimental group C, arrows presenting iron deposition. Perl's staining, 40X.

performed which showed statistically significant result between group B vs group C and between group A vs. group C (table-II).

Percent deposition of iron in control subgroups A was zero percent with $100 \%$ normal chondrocytes and matrix. Experimental subgroup B showed 20\% iron deposition in chondrocytes and matrix. $\mathrm{C}$ showed $70 \%$ iron deposition in chondrocytes and matrix (table-III).

Table-I: Comparison of iron deposition in the study groups.

\begin{tabular}{l|c|c|c|c}
\hline Parameters & $\begin{array}{c}\text { Group-A } \\
(\mathbf{n}=\mathbf{1 0})\end{array}$ & $\begin{array}{c}\text { Group-B } \\
(\mathbf{n}=\mathbf{1 0})\end{array}$ & $\begin{array}{c}\text { Group-C } \\
(\mathbf{n}=\mathbf{1 0})\end{array}$ & $\begin{array}{c}\boldsymbol{p} \text { - } \\
\text { value }\end{array}$ \\
\hline Iron & - & $0.20 \pm 0.42$ & $\begin{array}{c}1.30 \pm \\
0.48\end{array}$ & $<0.001$ \\
Deposition & - & 0.201 \\
\hline
\end{tabular}

Table-II: Inter-group comparison table (post hoc analysis).

\begin{tabular}{l|c|c|c}
$\begin{array}{l}\text { Group } \\
\text { Comparison }\end{array}$ & $\begin{array}{c}\text { Group-A } \\
\text { Vs. Group-B }\end{array}$ & $\begin{array}{c}\text { Group-B } \\
\text { Vs. Group-C }\end{array}$ & $\begin{array}{c}\text { Group-A } \\
\text { Vs. Group-C }\end{array}$ \\
\hline $\begin{array}{l}\text { Iron } \\
\text { Deposition }\end{array}$ & 0.45 & $<0.001$ & $<0.001$ \\
\hline
\end{tabular}

Table-III: Iron deposition in chondrocytes and matrix all four groups.

\begin{tabular}{l|c|c|c}
\hline $\begin{array}{l}\text { Iron } \\
\text { Deposition }\end{array}$ & $\begin{array}{c}\text { Group A } \\
(\mathbf{n}=\mathbf{1 0})\end{array}$ & $\begin{array}{c}\text { Group B } \\
(\mathbf{n = 1 0 )}\end{array}$ & $\begin{array}{c}\text { Group C } \\
(\mathbf{n}=\mathbf{1 0})\end{array}$ \\
\hline Normal & $10(100 \%)$ & $8(80 \%)$ & - \\
\hline$<10 \%$ & - & $2(20 \%)$ & $7(70 \%)$ \\
\hline$<20 \%$ & - & - & $3(30 \%)$ \\
\hline
\end{tabular}

In the Perl's stained slides iron deposition was obvious besides the other changed like change in the height of hypertrophy and proliferative zones and change in the diameter of chondrocytes. These changes were also more pronounced in the experimental group C.

\section{DISCUSSION}

It is proven in a previous study that the toxicity caused by the accumulation of iron in body tissues can result in cirrhosis, hepatic carcinoma, heart failure, diabetes mellitus, and osteoporosis ${ }^{16}$.

Current study shows that surplus maternal iron can be accumulated in the growth cartilage after crossing placenta. It is in accord with earlier studies showing iron accumulation in bone and cartilage and synovium. The amount of iron in cartilage is related with deteriorating clinical and imaging status of joint, as seen in haemophilic arthropathy. Considerable iron deposition inside the cartilage is established by Perl's staining, typically within and around chondrocytes, but also in lacunae without any evident active chondrocyte ${ }^{17}$. Synovial iron accumulation is also seen in Hereditary hemochromatosis patients and in patients with Rheumatoid arthritis. It is assumed that the iron deposition seen in the knee synovial membrane would come from blood entering the joint ${ }^{18}$. Besides iron, other mineral deposition in cartilage matrix always occurs before it occurs in bone because it provides the necessary, firm substrate for osteoblasts deposition ${ }^{19}$.

Comparable results were seen in another study (E.T omaszewska et al, 2019) showing maternal nutritional supplementation and its accumulation in fetal bones and growth plate. Maternal intake of dried fermented rapeseed meal increased the bone volume comparatively and decreased trabecular number and trabecular space in femoral epiphysis as well as increased the thickness of hyaline cartilage. The maternal nutrition changed the structure of mineral content of bone, as X-ray diffraction analysis shown the decrease of the mean size of the hydroxyapatite Nano crystallites in boars maternally supplemented with dried fermented rapeseed meal. This could be the effect of ionic substitutions of $\mathrm{Ca}$ ions in the hydroxyapatite structure, as the content of macro and micro components in ashes of bone samples was different in treatment groups. Inclusion of DFRSM to the diet of pregnant sows re- 
sulted in the decrease of the concentration of $\mathrm{Ca}$ and $\mathrm{P}$, and the increase of con- centration of $\mathrm{Cu}$ in the blood plasma of their offspring ${ }^{20}$.

\section{CONCLUSION}

This study proves that injudicious iron supplementation through pregnancy results in deposition of iron in epiphyseal growth plate of the fetus and it can have damaging effects on bones of fetus.

\section{CONFLICT OF INTEREST}

This study has no conflict of interest to be declared by any author.

\section{REFERENCES}

1. Dev S, Babitt JL. Overview of iron metabolism in health and disease. Hemodial Inter 2017; 21(1): S6-S20.

2. Bourassa M, Bergeron G, Gomes F. Multiple micronutrient supplementation during pregnancy: evidence review (P10-092-19). Current Develop Nutrit 2019; 3(Suppl-1): nzz034.P10-092-19.

3. Chandra I, Sun LZ. Iron status and choice of iron therapy during pregnancy: Advantages and disadvantages. Int J Reprod Contraception Obstet Gynecol 2015; 4(1): 1264-71.

4. Kumar D, Qureshi Z, Albadwawi M. Iron deficiency anemia in infants of Hatta Suburb-UAE. Int Arch Nurs Health Care 2019; 5(2): 5-21.

5. Rodríguez J, Mandalunis PM. A review of metal exposure and its effects on bone health. J Toxicol 2018; 2018(2): 4854152-55.

6. Menzies B. Iron intakes and food sources of iron in New Zealand adolescent females: University of Otago; 2020 [Internet] Available at https://ourarchive.otago.ac.nz/handle/10523/9960.

7. Baker BC, Hayes DJ, Jones RL. Effects of micronutrients on placental function: evidence from clinical studies to animal models. Reproduction 2018; 156(3): R69-R82.

8. Vieira J, Cunha E, de Souza J, Sant'Ana R, Zielak J, Costa-Casagrande $\mathrm{T}$, et al. Alendronate induces postnatal maxillary bone growth by stimulating intramembranous ossification and preventing premature cartilage mineralization in the midpalatal suture of newborn rats. Int J Oral Maxillofac Surg 2019; 48(11): 1494-503.

9. Pazzaglia UE, Reguzzoni M, Casati L, Sibilia V, Zarattini G, Raspanti M. New morphological evidence of the 'fate' of growth plate hypertrophic chondrocytes in the general context of endochondral ossification. J Anat 2020; 236(2): 305-16.

10. Iwaniak P, Dobrowolski P, Tomaszewska E, Hułas-Stasiak M, Tomczyk A, Gawron A. The influence of dexamethasone administered prenatally on cartilage of newborn spiny mouse (Acomys cahirinus) offspring. J Dev Orig Hlth Dis 2016; 7(3): 298-305.

11. Tomaszewska E, Dobrowolski P, Kwiecień M, WiniarskaMieczan A, Tomczyk A, Muszyński S. The influence of the dietary cu-glycine complex on the histomorphology of cancellous bone, articular cartilage, and growth plate as well as bone mechanical and geometric parameters is dose dependent. Biol. Trace Elem. Res 2017; 178(1): 54-63.

12. Elliott JJ, Miller CT, Hagarman JA, Kelley ST, Tardif SD, Hacker SO, et al. In: Management of Animal Care and Use Programs in Research, Education, and Testing. $2^{\text {nd }}$ edition. Boca Raton (FL): CRC Press/Taylor \& Francis; 2018. Chapter 29 [Internet] Available at: https://dokumen.pub/management-of-animal-careand-use-programs-in-research-education-and-testing-secondedition-1nbsped-1498748449-978-1-4987-4844-5-97814987484521498748457.html

13. Torabimehr F, Kazemi N, Hosseini SA. Effects of resistance and endurance training on HIF-1 $\alpha$ and VEGF in heart tissues of pregnant rats with cadmium toxicity. Gene Cell Tissue 2019; 6(1): 1-6.

14. Gong Y, Wang Y, Qu Q, Hou Z, Guo T, Xu Y, et al. Nanoparticle encapsulated core-shell hydrogel for on-site BMSCs delivery protects from iron overload and enhances functional recovery. J Control Release 2020; 320(2): 381-91.

15. Andrews F, Morris C, Kondratowicz G, Blake D. Effect of iron chelation on inflammatory joint disease. Annals Rheum Dis 1987; 46(4): 327-33.

16. Kot K, Kosik-Bogacka D, Ziętek P, Karaczun M, Ciosek Z, Łanocha-Arendarczyk N. Impact of varied factors on iron, nickel, molybdenum and vanadium concentrations in the knee joint. Int J Enviro Res Public Health 2020; 17(3): 813-15.

17. von Drygalski A, Barnes RF, Jang H, Ma Y, Wong JH, Berman Z, et al. Advanced magnetic resonance imaging of cartilage components in haemophilic joints reveals that cartilage hemosiderin correlates with joint deterioration. Haemophilia 2019; 25(5): 85158

18. Camacho A, Simão M, Ea H-K, Cohen-Solal M, Richette $P$, Branco J, et al. Iron overload in a murine model of hereditary hemochromatosis is associated with accelerated progression of osteoarthritis under mechanical stress. Osteoarthr Cartil 2016; 24(3): 494-502.

19. Pazzaglia UE, Reguzzoni M, Pagani F, Sibilia V, Congiu T, Salvi AG, et al. Study of endochondral ossification in human fetalcartilage anlagen of metacarpals: comparative morphology of mineral deposition in cartilage and in the periosteal bone matrix. Anat Rec 2018; 301(4): 571-80.

20. Tomaszewska E, Muszyński S, Dobrowolski P, Kamiński D, Czech A, Grela E, et al. Dried fermented post-extraction rapeseed meal given to sows as an alternative protein source for soybean meal during pregnancy improves bone development of their offspring. Livestock Sci 2019; 224(1): 60-68 